\title{
PARA DEFENDER É PRECISO FORTIFICAR: AS DEFESAS DA ILHA DE SANTA CATARINA DURANTE O SÉCULO XVIII
}

Jeferson dos Santos Mendes ${ }^{1}$

\begin{abstract}
RESUMO: O presente trabalho busca desenvolver uma análise das fortalezas construídas na Ilha de Santa Catarina durante o século XVIII. A emergência da coroa lusitana em manter o território da América do Sul e a construção do espaço geopolítico de conflito. O século XVIII viu nascer a preocupação com a manutenção do território da América meridional, notadamente a Ilha de Santa Catarina como um centro de gravidade entre o norte, o centro e o sul da colônia. Dessa forma, a coroa buscou limitar os riscos de uma invasão espanhola na Ilha reforçando o porto e as barras Norte e Sul com fortes, fortalezas e fortins.
\end{abstract}

PALAVRAS-CHAVE: fortalezas; Ilha de Santa Catarina; América meridional.

\section{TO DEFEND IS NECESSARY TO FORTIFY: THE DEFENSES OF THE ISLAND OF SANTA CATARINA DURING CENTURY XVIII}

\begin{abstract}
The present work seeks to develop an analysis of the fortresses built on the Island of Santa Catarina during the 18th century. The emergence of the Lusitanian crown in maintaining the territory of South America and the construction of the geopolitical space of conflict. The eighteenth century saw the concern with the maintenance of the territory of South America, notably the Island of Santa Catarina as a center of gravity between the north, center and south of the colony. In this way, the crown sought to limit the risks of a Spanish invasion on the Island by strengthening the port and the North and South bars with forts, forts and fortresses.
\end{abstract}

KEYWORDS: fortresses; Santa Catarina Island; South America.

\section{PARA DEFENDER ES NECESARIO FORTIFICAR: LAS DEFENSA DE LA ISLA DE SANTA CATARINA DURANTE EL SIGLO XVIII}

RESUMEN: El presente trabajo busca desarrollar un análisis de las fortalezas construidas en la Isla de Santa Catarina durante el siglo XVIII. La emergencia de la corona lusitana en mantener el territorio de América del Sur y la construcción del espacio geopolítico de conflicto. El siglo XVIII he detectado la preocupación por el mantenimiento del territorio de América meridional, notadamente la Isla de Santa Catarina como un centro de gravedad entre el norte, el centro y el sur de la colonia. De esta forma, la corona buscó limitar los riesgos de una invasión española en la Isla reforzando el puerto y las barras Norte y Sur con fuertes, fortalezas y fortines.

PALABRAS CLAVE: fortalezas; Isla de Santa Catarina; América del sur.

\footnotetext{
${ }^{1}$ Doutorando em História e Cultura do Brasil pela Faculdade de Letras da Universidade de Lisboa, Portugal. 


\section{INTRODUÇÃO}

Em 1680, uma pequena expedição, chefiada por Dom Manuel Lobo, então governador da Capitania do Rio de Janeiro, ao estuário do Rio da Prata procurou estabelecer os limites territoriais do império português. Nesse local, construiu um pequeno fortim na margem esquerda do Rio da Prata, em frente a Buenos Aires. A fundação da Colônia do Sacramento gerou lutas cruentas e seculares entre as coroas ibéricas. Por outro lado, provocou o caldeamento de militares europeus, índios silvícolas e negros africanos. Além disso, despertou grandes tensões na manutenção do território da América Meridional. O Rio Grande de São Pedro e a Ilha de Santa Catarina imiscuíam-se no tabuleiro. O jogo das coroas ibéricas envolvia a tríade Colônia do Sacramento, Rio Grande de São Pedro e Ilha de Santa Catarina. A primeira jogada da coroa portuguesa foi avançar seu território até à região mais setentrional do Rio da Prata, enquanto os espanhóis gradativamente movimentavam suas peças no entorno da América Meridional.

Situada a meio caminho entre o Rio de Janeiro e o Rio da Prata, a Ilha de Santa Catarina foi parada obrigatória de viajantes europeus a partir do século XVI. A grande maioria das embarcações europeias, além de explorar a Ilha, buscava um porto privilegiado para se refazer de aprovisionamentos, água, víveres e alimentos frescos. A atracagem favorecia as viagens de ida e volta à embocadura do Rio da Prata, destino de grande parte das embarcações europeias no extremo sul da América².

A descoberta do ouro nos sertões mineiro e paulista forçou o governo luso-brasileiro à expansão e à consolidação colonial rumo ao sul da América. O comércio e o roubo imiscuíam-se e serpenteavam no vasto território da América Meridional, tendo como grande articulador o Rio da Prata ${ }^{3}$. Entretanto, a ação lusitana confrontava com a expansão espanhola no mesmo espaço. Gradativamente, as forças hispânicas das missões jesuíticas avançavam ao Paraguai, para leste dos rios Paraná e Uruguai e demais províncias adjacentes ao Rio da Prata. A Ilha, nesse imbróglio, ganhou relevância e importância estratégica de manutenção e apropriação efetiva do território.

\footnotetext{
2 Sobre a constituição histórica de "um espaço catarinense", ver MARTINELLO, André Souza. Geografia Histórica, discursos espaciais e construção territorial de Santa Catarina. Tese (Doutorado) em Geografia Humana, USP, 2016.

${ }^{3}$ Mais informações sobre o contrabando na região do Rio da Prata, ver CANABRAVA, Alice Piffer. O comércio português no Rio da Prata, 1580-1640. São Paulo: Editora da Universidade de São Paulo, 1984.
} 
A 26 de março de 1726, foi criada a vila do Desterro. Contudo, como lembra Prado Jr (1953, p. 84), "não havia aí mais que uma população escassa e constituída em sua quase totalidade pelas guarnições militares que defendiam as fronteiras da colônia”. Quanto à Ilha de Santa Catarina, durante quase três séculos, a densidade demográfica da Ilha pouco se alterou ${ }^{4}$ : índios silvícolas, autoridades coloniais e militares, fugitivos, escravos se imiscuíam entre as elites locais. A assimétrica relação de poder, o caldeamento populacional provocava sisudas querelas entre índios autóctones e europeus. A população local, insegura, fugia para os bosques, as montanhas e os sítios mais seguros, longe dos nativos. Sem fortalezas, sem um corpo militar permanente, a população vivia entre a beleza natural da Ilha e o medo iminente da floresta.

Em março de 1735, aportava no Rio de Janeiro, o brigadeiro José da Silva Pais. Tinha a incumbência de sucessor imediato de Gomes Freire de Andrada, no governo do Rio de Janeiro, em sua ausência. A 9 de junho de 1736, Gomes Freire passou uma série de instruções ao brigadeiro. Entre elas: tomar posse do território do Rio Grande, ocupando e fortificando a região; defender a Colônia do Sacramento dos constantes assédios espanhóis, sobre cerco desde outubro de 1735 a setembro de $1737^{5}$; além da tomada de Montevidéu e fundar uma fortificação em Maldonado. Entretanto, a falta de água e madeira impossibilitou qualquer fundação, restando como única alternativa fortificar o Rio Grande de São Pedro, com o presídio Jesus-Maria-José, em princípio de 1737 (POSSAMAI, 2004, p. 170).

Um ano depois, a coroa transferia a jurisdição da Ilha de Santa Catarina, Rio Grande de São Pedro e Laguna (1742) da Capitania de São Paulo para o Rio de Janeiro. A partir daí, com mais frequência, a Ilha passava a constar nos ofícios e missivas das autoridades coloniais e lisboetas. A conservação do território entrava na ordem do dia da coroa portuguesa. José da Silva Pais foi nomeado governador. A ele foi onerado as bases defensivas e organizativas.

\footnotetext{
${ }^{4}$ Caio Prado Jr (1945, p. 30) calcula em 3.000.000 de habitantes a população brasileira no dobrar do século XVIII. Duperrey Lesson, navegador francês, quando aportou na Ilha, contabilizou 10.000 pessoas. Em Nossa Senhora do Desterro, capital da capitania, existiam, segundo o navegador, 6.000 indivíduos, essas "distinguemse em três classes de habitantes, os brancos, os mulatos e os negros; a última é quase em sua totalidade composta de escravos" escreveu Lesson em seu diário. LESSON, Duperrey. Voyage autour du monde, exécuté par ordre du Roi, sur la corvette La Coquille, pedant les années..., In: HARO, Martim Afonso de Palma de. Ilha de Santa Catarina, relatos de viajantes estrangeiros nos séculos XVIII e XIX. 4ª ED. Florianópolis: UFSC/Lunardelli, 1996, p. 268).

${ }^{5}$ Sobre o certo à Colônia do Sacramento, ver: POSSAMAI, Paulo César. O recrutamento militar na América Portuguesa, o esforço conjunto para a defesa da Colônia do Sacramento (1735-1737). In: Revista Histórica, Departamento de História da Universidade de São Paulo. 2004. n. 151, 2º semestre, pp. 151-180.
} 
Durante o comando, três fortalezas foram erguidas na Barra Norte e uma na Barra Sul (SILVA, 2008, p. 56). Ao longo do século XVIII outras oito fortificações foram construidas.

Por outro lado, é importante lembrar que, o sistema defensivo é produto de estados soberanos em busca de afirmação territorial (KEEGAN, p. 157). Enquanto as estruturas defensivas medievais representavam "a expressão simbólica do poder da nobreza", as fortalezas modernas articulavam novas estruturas geométricas. Nesse caso, representavam a feitura concreta e simbólica do domínio lusitano. Ao mesmo tempo, marcavam a eficiente soberania do reino. Vale lembrar, que a partir do século XVII ocorreu um melhoramento logístico nos sistemas construtivos. Os baluartes metamorfosearam de acordo com a alternância do sistema bélico. A própria arte da guerra, no que diz respeito às fortalezas, sofreu alterações significativas: traçados diferenciados (menos ornamentados); alterações arquitetônicas (desenhos geométricos precisos); eram capazes de neutralizar o avanço tecnológico, principalmente dos canhões (BEBIANO, 2000, p. 370).

\section{AS FORTALEZAS DA BARRA NORTE}

Segundo alguns autores as principais razões para a criação da Capitania da Ilha de Santa Catarina foram de ordem política e estratégico-militar. A recente fundação da Colônia do Sacramento exigia a implantação de um sistema defensivo litorâneo (PIAZZA, 1983, p. 123). Coube ao brigadeiro iniciar o sistema de defesa. Na carta endereçada à Gomes Freire de Andrada, em 21 de junho de 1737, Silva Pais é enfático ao afirmar "eu sou o primeiro que reconheço é preciso na ilha de Santa Catarina haja alguma fortificação [...] e isso mesmo mandei dizer a Santos". Preocupava-se ainda: "é sem dúvida nos seria mui sensível o perdêla" (Carta do brigadeiro José da Silva Pais, 1978, vol. 98, p. 216).

Para Silva Pais, a defesa da Ilha dependia de outro fator - não menos importante -, que era vincular o governo do Rio Grande à Ilha. Essa estratégia favoreceria a manutenção de ambos os territórios. Além disso, auxiliaria com mais rapidez o envio de tropas, mantimentos e instrumentos bélicos. Dessa forma, salientava o brigadeiro...

[...] ordem para sua execução, e também para unir aquela ilha a esse governo, reconhecendo que só dele poderá ser fortificada, conservada e socorrida, e por não ser justo que as suas dependências sejam separáveis das do Rio Grande, porque, ficando umas e outras forças em diferentes governos 
na necessidade, se obrará com mais lentidão (Carta de Gomes Freire de Andrada p. 109-125).

Por outro lado, as preocupações com a defesa e conservação da Ilha de Santa Catarina iniciaram em 1709. Entretanto, os trabalhos só começaram trinta anos depois, no governo do brigadeiro José da Silva Pais ${ }^{6}$. Este levou do Rio de Janeiro alguns civis e um grupo de “índios mansos” para iniciar a construção das cidadelas?. Como lembra Izecksohn "a organização de tropas de flecheiros e de bandos de escravos se constituiria em referência para a segurança do território e de suas elites” (2014, p. 490). A estratégia arquitetada num primeiro momento era empreender três fortificações na parte norte: na ilhota de Anhatomirim, no mesmo ano em que Silva Pais tomou posse, foi iniciada a construção da fortaleza de Santa Cruz (1739); em frente à ilha de Anhatomirim, em Ponta Grossa, no ano seguinte, iniciou a construção da fortaleza de São José de Ponta Grossa (1740); e, no mesmo ano, foi iniciada a construção da fortaleza de Santo Antônio (1740), na ilha dos Ratones.

Ao longo das construções, o gabinete português considerava a ilha inexpugnável. Com os três pontos fortificados, tanto a coroa como ao governo luso-brasileiro davam sinais de confiança. Além disso, mantinham, aparentemente, um triângulo supostamente intransponível. As limitações de poderio e principalmente de alcance - da fortaleza de Santa Cruz à de Ponta Grossa, a distância era de $6 \mathrm{~km}$, a mesma distância tinha a primeira fortaleza com a de Ratones, sendo esta última $8 \mathrm{~km}$ distante de Ponta Grossa -, não foram suficientes para conter os ânimos do governo metropolitano. Com excelente sistema defensivo, possuía todos os requisitos para efetuar a mais exemplar resistência no caso de um ataque por forças estrangeiras, considerava a coroa lusitana. "As fortificações que tenho feito nas três paragens que mandei dizer a V. Mage. me parecião mais convenientes”, escreveu o brigadeiro José da Silva Pais (PIAZZA, 1988, p. 132).

Se a ideia portuguesa era que os invasores ficassem sobre constantes fogos cruzados, na prática, a distância entre as fortalezas impedia qualquer estratégia. Praticamente, as

\footnotetext{
${ }^{6}$ O brigadeiro José da Silva Pais tomou posse a 7 de março de 1739 do governo da Capitania de Santa Catarina. Foi o responsável pela construção de três fortalezas na parte norte da ilha e de uma fortaleza na parte sul. Foi destituído em 2 de fevereiro de 1749, quando retornou ao Rio de Janeiro e, posteriormente, para Portugal.

${ }^{7}$ Os civis contratados foram: Manoel Rodrigues de Araújo, Comissário de Mostras; José Inácio de Souto-Maior, Demarcador e Repartidor; Felix Gomes de Figueiredo, Provedor da Fazenda; capitão José Cardoso Ramalho, engenheiro. In: PIAZZA, Walter F. O Brigadeiro José da Silva Paes: estruturador do Brasil Meridional. Florianópolis: FURG/UFSC, 1988, p. 128.
} 
fortalezas serviriam apenas como monumentos simbólicos de defesa, já que as distâncias entre as três fortificações eram muito grandes para o armamento bélico da época.

Periodicamente, José da Silva Pais comunicava o Conselho Ultramarino a relação das despesas com as fortalezas (Consulta do Conselho Ultramarino, 1978, vol. 98, p. 215). A resposta da coroa ao brigadeiro era que intensificasse os trabalhos (Consulta do Conselho Ultramarino, 1978, vol. 98, p. 215), otimizando o espaço defensivo. Contudo, a prossecução da empresa só traria retorno satisfatório, segundo o brigadeiro, com a criação de um regimento para guarnecer as fortalezas já construídas na capitania (Consulta do Conselho Ultramarino, 1978, vol. 98, p. 215). Eram necessárias, segundo ele, "6 companhias de 60 homens cada uma ficavam suficientemente guarnecidas as tais fortalezas" (Conselho do Conselho Ultramarino, 1936 (1928), vol. 50, pp. 113-114).

No final de dezembro de 1840, George Anson, um navegador inglês, a serviço da esquadra britânica, ancorou na Ilha de Santa Catarina e comentou sobre as primeiras construções feitas pelo brigadeiro José da Silva Pais.

O Brigadeiro dom José da Silva Pais, Governador desta colônia, tem a reputação de ser um hábil engenheiro; e não se pode negar que ele entende do seu assunto, pelo menos em parte, estando certo das vantagens que a construção de algumas novas obras acarretam, [...] existem ainda três outros fortes para defender a entrada do porto, nos quais ainda trabalham, não estando nenhum deles prontos. O primeiro destes fortes, chamado de São João, foi batizado numa ponta da Ilha de Santa Catarina, do lado da Ilha dos Papagaios; o segundo, em forma de meia-lua, está sobre a Ilha de Santo Antônio, e o terceiro, que parece o mais considerável e que tem o aspecto de uma fortaleza regular, está sobre uma ilha próxima do continente, no qual o Governador reside (ANSON, 1996, p. 64).

Por outro lado, José da Silva Pais queixava-se dos planos de defesa para a Ilha de Santa Catarina. Nem todas as "plantas" eram eficientemente satisfatórias ao brigadeiro. "Eu estimo muito a planta que V. S. [Gomes Freire de Andrada] me remete, por ser mais correta que algumas que as minhas mãos haviam chegado". O brigadeiro, apenas aguardava ordens para a "execução" (Carta de Gomes Freire..., p. 109-125). As fortificações junto com as igrejas e conventos se imiscuíam na paisagem urbanística colonial. Muito presente nas edificações das fortalezas do Brasil colonial foram os estilos de arquitetura rococó, maneirista e barroco (TIRAPELI, 2006, p. 7). Na Ilha de Santa Catarina, é indiscutível a presença de 
traços lusitanos na arquitetura ${ }^{8}$. Organizadas estrategicamente, "as fortalezas ficavam em pontos elevados da encosta e frequentemente em uma necessária passagem de embarcações" (CUSTÓDIO, jan./jun. 2011, p. 179).

É importante lembrar que, a vida numa fortaleza exigia de soldados e comandantes certo controle disciplinar e divisão de funções. A boa conduta - mantida através de uma rígida rotina burocrática - era essencial para acondicionar certas medidas preventivas. Andrea Doré, ao falar sobre a presença portuguesa no Oriente, comparou a fortaleza ao navio, visto os dois serem "um espaço de reclusão", contudo o baluarte funciona "como um enclave em terra firme, no litoral" (DORE, A. C, p. 91-116, 2009). Por outro lado, a transformação de cada baluarte numa unidade militar era capaz de conservar bilateralmente o poder colonial e metropolitano. Contudo, nem sempre ou quase nunca a fortaleza foi um espaço dinâmico de cordialidade e submissão. Nos ofícios e relatórios das autoridades coloniais é possível verificar a existência de abusos de poder, corrupção e um longo índice de indisciplina por parte dos subordinados à coroa.

Ainda durante a construção das fortalezas, para superar a falta de mão de obra lusobrasileira o governador utilizou de mãos indígenas. A 15 de fevereiro de 1748, José da Silva Pais informou a possibilidade de "tirarem-se os índios que forem necessários para o serviço das fortalezas e das obras". Esses índios deveriam sair da "aldeia de Itanhaém na Vila da Conceição, da Capitania de S. Paulo" e passarem imediatamente para os trabalhos nas fortificações da Ilha. Além de mão de obra indígena, o comandante preocupava-se com a vida religiosa. Para as construções, ordenou o envio de capelões às três fortificações da barra, pois todas as ermidas estavam prontas (Cartas do Brigadeiro José da Silva Paes, vol. 50, pp. 117)

\section{AS FORTALEZAS DA BARRA SUL}

Formado o triângulo defensivo da Barra Norte, o brigadeiro iniciou os trabalhos na Barra Sul. Em 1741, na Ilha de Araçatuba, começou a construção da fortaleza de Nossa Senhora da Conceição.

Depois de organizar o do sistema defensivo (fortalezas), militar (regimentos) e os principais núcleos populacionais (povoamento), o governador José da Silva Pais foi

\footnotetext{
${ }^{8}$ Mais informações em: SOUZA. Sara Regina Silveira de. A presença portuguesa na Arquitetura da Ilha de Santa Catarina. Florianópolis: Fcc, 1981.
} 
Para defender é preciso fortificar: as defesas da Ilha de Santa Catarina durante o século XVIII Jeferson dos Santos Mendes

substituído pelo coronel Manoel Escudeiro de Souza (1749-1753). O brigadeiro se recolheu para Lisboa (BRITO, 1829, p. 22). Por ordem régia, a coroa portuguesa ordenou ao exgovernador que informasse o estado das fortalezas e guarnições militares da Ilha de Santa Catarina, além das providências necessárias para mantê-las em constante segurança (Ordem Régia, Lisboa, 1936 (1928), vol. 50, p. 114).

No governo de Manoel Escudeiro, as fortalezas não sofreram alterações significativas. Administrativamente a Ilha recebeu uma leva ainda maior de colonos, e o coronel fundou outros núcleos populacionais ${ }^{9}$.

Nesse momento, as negociações europeias pelas possessões da América Meridional causaram lutas cruentas e seculares. O Tratado de Madrid (1750) - tentativa frustrada de paz entre as coroas ibéricas - previa a troca da Colônia do Santíssimo Sacramento pelos Sete Povos das Missões. As dificuldades em transladar os índios missioneiros - que se recusaram a sair de suas possessões - originou no conflito entre tropas luso-espanholas contra índios guaranis das Reduções Jesuíticas na chamada Guerra Guaranítica (1751-1756) ${ }^{10}$.

No governo do coronel Francisco António Cardoso de Menezes (1761-1765), os trabalhos e a preocupação com as defesas voltaram a assombrar a administração colonial. Esse era acusado de empregar "os moradores sujeitos a trabalhos sem o menor estipêndio nas

\footnotetext{
${ }^{9}$ É importante lembrar que entre 1748 e 1756 foram enviados, em média, seis mil casais das Ilhas atlânticas (Açores e Madeira) e da região do Minho. Para maiores informações ver: PIAZZA, F. Walter. Santa Catarina, sua história. Florianópolis: Ediufsc, Lunardelli, 1982, p. 139-140. Para mais informações sobre a imigração açoriana na Ilha de Santa Catarina consultar: BRITO, Paulo José Miguel de. Memória política sobre a Capitania de Santa Catarina. Lisboa: Edição da Acadêmia de Ciências de Lisboa, 1829, p. 23-25; BOITEUX, Lucas Alexandre. Açorianos e madeirenses em Santa Catarina. Revista do Instituto Histórico e Geográfico Brasileiro. volume 0219, 1953, CABRAL, Oswaldo. Os açorianos. In: Anais do $1^{\circ}$ Congresso de história catarinense. Florianópolis: Imprensa Oficial do Estado, v. 2, 1950, p. 503-608; LAYTANO, Dante de. Corografia de Santa Catarina. Revista do Instituto Histórico e Geográfico Brasileiro. Rio de Janeiro, v. 245, out-dez, 1959, p. 3-187, p. 158-159; MENESES, Avelino de Freitas. A conjuntura dos Açores à data da colonização setencista de Santa Catarina. In: Anais do Simpósio comemorativo ao cinqüentenario do $1^{\circ}$ Congresso de Historia Catarinense e 250 anos da presença açoriana em Santa Catarina. Florianópolis: Instituto Histórico e Geográfico de Santa Catarina, 1998, p. 41-52; MADEIRA, Artur Boavida. População e emigração nos Açores - 1766-1820. Cascais: Patrimonia, 1999; MENEZES, Avelino de Freitas. Os açorianos nas encruzilhadas de Setecentos II - economia. Ponta Delgada: Universidade dos Açores, 1995; MENEZES, Avelino de Freitas. Os açorianos nas encruzilhadas de Setecentos I - poderes e instituições. Ponta Delgada: Universidade dos Açores, 1993; PIAZZA, Walter F. A epopéia açórico-madeirense - 1748-1756. Florianópolis: Editora da UFSC, Editora Lunardelli, 1992; PIAZZA, Walter F. O Povoamento Açoriano. In: Osvaldo Ferreira de Melo (Coord.). História Sócio-Cultural de Florianópolis. Florianópolis: Clube Doze de Agosto-Editora Lunardelli-IHGSC, p. 53-89, 1991; PRADO JR, Caio. Formação do Brasil contemporâneo, colônia. 2ed. São Paulo: Editora Brasiliense, 1953, p. 40, 83-84, 109, 114, 156, 199; RODRIGUES, José Damião. Da periferia insular às fronteiras do império: colonos e recrutas dos Açores no povoamento da América. In: Anos 90. Porto Alegre, v. 17, n. 32, p. 17-43, dez. 2010.

${ }^{10}$ Mais informações sobre a Guerra Guaranítica pode ser encontrada em: GOLIN, Tau. A guerra guaranítica, como os exércitos de Portugal e Espanha destruíram os Sete Povos dos jesuítas e índios guaranis no Rio Grande do Sul. 2.ed. Passo Fundo: Ediupf, 1999.
} 
fortalezas, em exercícios militares, sofrendo aviltantes espancamentos" (BOITEUX, volume 0219, 1953, p. 168). Em sua administração, o engenheiro militar José Custódio de Sá e Faria construiu mais dois fortes: o forte de São Francisco Xavier, na praia de Fora, lado Norte da Vila do Desterro, armado com dois canhões; e o forte de Santana, no estreito entre a ilha e o continente, lado da ilha. Dois anos depois, foram iniciadas as construções de mais dois fortes: forte de São Caetano, ao norte da ilha de Santa Catarina, próximo da fortaleza de São José da Ponta Grossa, para o lado de oeste, com 6 canhões; forte São Luiz, na praia de Fora, lado Norte da vila do Desterro, com quatro canhões, distante apenas um quilômetro do forte São Francisco Xavier (CALDAS, 1992, pp. 35-37). Eram essas as fortificações existentes na Ilha, acrescidas de um fortim levantado na entrada da lagoa da Conceição, no lado oriental.

Dessa forma, durante a administração de Francisco António Cardoso de Meneses, José Custódio de Sá e Faria foi escalado para finalizar o sistema defensivo da Ilha, sendo responsável pela construção dos fortes de São Francisco Xavier e Santana ${ }^{11}$. No dia 4 de abril de 1763, o brigadeiro escreveu ao irmão do marquês de Pombal, Francisco Xavier de Mendonça Furtado, ressaltando as obrigações que tinha com os desenhos e demais configurações. Dizia ele: "e há pouco tempo chegado da Ilha de Santa Catarina onde fui mandado pelo meu general a reedificar as suas fortalezas, e projetar e erigir alguns fortes que se faziam precisos para segurar os passos mais abertos daquela Ilha, da qual também remeterei o plano e os das suas fortalezas" (Carta de José... 1902, tomo LXV, primeira parte, pp. 115-117).

De Lisboa, Martinho de Melo e Castro recomendou ao marquês do Lavradio, entre outras providências, a necessidade particular a Ilha de Santa Catarina e determinando a transferência do brigadeiro José Custódio de Sá e Faria de São Paulo para o Sul (Oficio de, 1978, vol. 98, p. 221). Formado na Academia Militar das Fortificações de Portugal, José Custódio especializou-se em arquitetura clássica e fortificação. O levou a indicação para projetar a tumba do rei d. João V. Aos poucos, Sá e Faria adquiria respeito e consideração da coroa. Em 1750, foi promovido a sargento-mor e designado à Expedição da América Portuguesa integrando a equipe responsável pela demarcação prevista no Tratado de Madrid.

\footnotetext{
${ }^{11}$ O forte de São Francisco Xavier "situado a montante de uma praia no fim de um caminho que ia da Vila construído de frente para a baía do norte (Praia de Fora)". Já o de Santana ou Sant'Ana, situado na Ilha, "na ponta mais próxima do continente, no lugar que então se denominava de Estreito". CABRAL, Oswaldo Rodrigues. As defesas da Ilha de Santa Catarina no Brasil, Colônia. Rio de Janeiro: Conselho Federativo de Cultura, 1972, p. 39-40.
} 
Depois de uma pequena parada no Rio de Janeiro, partiu rumo ao Rio Grande, onde recebeu o cargo de governador. Projetou uma matriz fortificada em Viamão - capital da capitania além de um forte e a matriz em Taquari e Triunfo. Após o fracasso militar no Rio Grande, Sá e Faria retornou à capital do reino para projetar um novo sistema de defesa diante da eminente ameaça causada pela esquadra de Pedro de Cevallos. Em 1777, as preocupações recaíram sobre a Ilha de Santa Catarina, e o brigadeiro foi logo enviado para remodelar e preparar as defesas. Ao chegar, Sá e Faria comentou com preocupação a distância entre as fortalezas e as ineficiências das mesmas (WEIMER, pp. 132-133).

Em meados de novembro de 1763, um navegador francês, Antonie Joseph Pernetty, navegou e aportou na Ilha de Santa Catarina. Ao descrever os fortes da Barra Norte relatou:

Existem na baía onde ancoramos três fortes que defendem a entrada; o primeiro está situado na ponta da ilha e se chama Forte da Ponta Grossa; em frente está o segundo, chamado Forte de Santa Cruz. Seu aspecto é muito vantajoso porque está construído numa plataforma sustentada por arcadas. É onde reside o Comandante. O terceiro forte está mais próximo da Vila. Dáse-lhe o nome de Forte da Ilha Ratones. Ancoramos entre os três; o Comandante nos fez compreender por sinais que este era o melhor ancoradouro: tinha uma boa visão e estava perto da terra firme, o que é muito mais cômodo (PERNETTY, 1996, p. 80).

Durante a atracagem, Pernetty não poupou elogios às fortalezas e ao sistema defensivo desenvolvido pelo brigadeiro José da Silva Pais. A parada para abastecimento de aguada e víveres de muitos viajantes imiscuia-se às construções em curso. É interessante notar que as fortalezas da Ilha de Santa Catarina começaram a sofrer duras críticas somente após a conquista espanhola (1777).

Os engenheiros nomeados no Reino eram responsáveis pelas obras em toda América meridional. A grande maioria dos arquitetos vagavam de uma capitania para outra. $\mathrm{O}$ sargento-mor Manuel Vieira Leão foi encarregado por Gomes Freire de Andrada (17631767), de elaborar o mapa cartas topographicas da capitania do Rio de Janeiro e, posteriormente, de projetar a primeira igreja da capitania, a de São Pedro na cidade de Rio Grande (provavelmente também projetou a de Triunfo). Após a ocupação castelhana os bens da igreja foram levados para Viamão (WEIMER, 2006, p. 114). Manuel Vieira Leão, posteriormente, ocupou o cargo engenheiro militar da Ilha de Santa Catarina.

Os engenheiros militares eram escolhidos, na maioria das vezes, pela habilidade com os desenhos. A implementação do ensino de arquitetura em Portugal - pelo menos no século 
XVII - notadamente esteve voltado para as defesas e construções militares. Em 13 de junho de 1647, foi fundada a primeira escola de ensino militar em Portugal, sediada na Ribeira das Naus, em Lisboa ${ }^{12}$. Luís Serrão Pimentel, engenheiro-mor do reino e professor do curso, escreveu um manual para desenhar as fortificações, o qual, além de ser o primeiro em língua portuguesa, o Mhetodo Lusitanico de Desenhar as Fortificações das Praças Regulares e Irregulares, produzido em 1680, transformar-se-ia em obra basilar para as construções em todo o reino. Outra obra de referência é de Manoel de Azevedo Fortes, $O$ Engenheiro Portugues, escrita em 1728. Este último, como engenheiro-mor do reino, esteve pessoalmente na Ilha de Santa Catarina, em 1740, vistoriando as construções feitas pelo governador (Ver Tonera, e Ferreira, 2009).

A nomeação dos comandantes das fortalezas passava por rígidas avaliações. Por norma, os responsáveis pela defesa haviam prestado inúmeros serviços à coroa. Mesmo assim, a grande maioria era comandante com parca envergadura militar, o que acirrava o descontentamento das autoridades coloniais. Enquanto Manoel Cunha Menezes pedia a substituição de alguns comandantes das fortalezas (Oficio do Governador... 1910, vol. 32, p. 284), na fortaleza da Barra do Sul, onde estava o sargento-mor Manuel Vieira Leão, o comandante Antônio Carlos Furtado de Mendonça queixava-se: "preciso providência muitas coisas" (Carta do general, 1983, vol. 103, p. 50).

Considerando o trabalho dos engenheiros militares, outro que merece destaque é Francisco José da Rocha. No governo de Sousa de Menezes (1765-1775), foi o engenheiro responsável pela construção do forte de São Caetano, construído em 1765, nas proximidades da fortaleza de São José da Ponta Grossa e, em 1771, construiu o forte de São Luís. "A preocupação de fazê-los enfrentar não só uma situação bélica, fosse a de dificultar um desembarque nas praias situadas, à época, nos fundos da Vila Capital, como também obstar a

\footnotetext{
${ }^{12}$ Durante o século XVIII a coroa lusitana reforçou o ensino de engenharia militar nas colônias. Em 1699, por Carta Régia, a coroa lusitana determinou a criação de aulas militares no Brasil. Foram contempladas as capitanias de Pernambuco, Maranhão, Rio de Janeiro e Bahia. Nos primeiros anos dos setecentos, a coroa enviou oficiais de granadeiros com o intuito de instruírem outros no ofício e determinou o ensino de engenharia. Nas aulas de ensino militar - Bahia 1714, Pernambuco 1788 - eram ministradas aulas sobre fortificações e artilharia. Seguindo os mesmos métodos desenvolvidos na Universidade de Coimbra e na Real Academia da Marinha de Lisboa. Em 1738, no Rio de Janeiro, os militares tinham aula de Teoria da artilharia e uso de fogos artificiais, ministradas pelo engenheiro sargento-mor José Fernando Pinto Alpoim. No final do século, portanto 1795, no Recife, foram criadas aulas de geometria. PEREIRA, Potiguara. Engenharia Militar. In: VARGAS, Milton (Org). História da técnica e da tecnologia do Brasil. São Paulo: Editora da Universidade Estadual Paulista, Centro Estadual de Educação Tecnológica Paula Souza, 1994, p. 166-167.
} 
atracação de pequenas embarcações", escreveu Oswaldo Cabral em seu clássico trabalho sobre as fortalezas na Ilha de Santa Catarina no período colonial (CABRAL, 1972, p. 39).

A 9 de julho de 1774, Sebastião José de Carvalho e Mello finalizava uma longa missiva ao vice-rei do Brasil, marquês do Lavradio. Ao enviar as instruções secretas e o chamado Plano Militar, concedia plenos poderes ao vice-rei para a defesa e restauração do extremo sul do Brasil. A quinta instrução do Plano Militar expedia o valor das defesas em terra. "Que a fortaleza principal e fortes da referida Ilha sejam armados com toda a artelharia, carretame, palamenta, polvora, bala e petrechos possiveis para fazerem uma vigorosa defesa nos casos de surpresas ou de ataques", ordenava o marquês de Pombal (Carta do Marquês de Pombal..., 1978, vol. 98).

Antônio Carlos Furtado de Mendonça (1775-1777), último comandante português antes da conquista castelhana de 1777, poucos meses após ocupar o cargo de comandante da Ilha de Santa Catarina, demonstrou insatisfação com as defesas ali existentes e prontamente, requisitou instrumentos para fortificá-la. "Não tenho o que preciso", dizia ele ao tenentegeneral João Henrique Böhm. Com os recursos indisponíveis era impossível construir um sistema de defesa eficiente. Nas correspondências endereçadas ao comandante do Exército do Sul, queixava-se constantemente das necessidades de organização e do descumprimento do vice-rei no envio dos artigos necessários para tal empresa. Cobrava mais apetrechos de artilharia para posicionar nos sistemas defensivos. Se não bastasse a ausência de instrumentos bélicos, o general queixava-se da falta de soldados nas guarnições, pois "toda a gente capaz, que tinha desse exercício a levou José Marcelino para esse Continente". Justificando o desastroso "estado de decadência", escreveu nitidamente consternado,

Eu aqui vou labutando com esta defesa, quanto me é possível; mas é bem certo, que o estado da minha saúde, não premite o eu fazer tudo o que quero, e ao mesmo tempo vejo que não tenho o que preciso: eu tenho pedido ao Sr. Marquês Vice-Rei o que entendo é preciso; ele sim tem mandado parte do que peço; mas não o que é preciso, e já me mandou dizer, que não sabe o como me há de contentar; mas eu com todo o desafogo irei continuando a pedir o que entender, e o que mais tenho sentido que me não mande, é, um parque de artelharia para puder fazer um bataria bulante para puder acudir as deferentes partes aonde for atacado, e também ao menos duas companhias de artelharia, pois ainda que este regimento leve ensino de artelharia, hoje toda a gente capaz, que tinha desse exercício a levou José Marcelino para esse Continente, e o único oficial, que tinha capaz para este exercício está hoje no Regimento de Chichorro. Eu aqui estou aturando a molidão e inação de Eusébio Antônio que se não pode duvidar, que é bom oficial; mas tem as más circunstâncias referidas: Creia V. Ex. que me vejo na maior 
consternação de trabalho, que, é possível; V. Ex. aqui esteve, e com as suas belas luzes viu o estado da decadência em que isto estava (Carta do general, 1983, vol. 103, p. 49-50).

Antônio Carlos Furtado de Mendonça empreendeu algumas mudanças às obras já feitas. Vale relembrar que todas as construções, obras, faxinas, fortins já estavam construídos em 1775, ano em que assumiu o posto de comandante-das-armas. A tarefa era otimizar as construções, sem risco de serem obsidiadas por mar ou terra. Keegan explica com propriedade o papel e as principais características de um sistema de fortificações:

Uma fortaleza não é um lugar simplesmente de proteção contra um ataque, mas também de defesa ativa, um centro onde os defensores estão protegidos da surpresa ou da superioridade numérica e uma base da qual podem fazer surtidas para manter os predadores à distância e impor controle militar sobre a área por que se interessam. Há uma simbiose entre a fortaleza e sua circuvizinhança. [...] Uma fortaleza, ao contrário, deve controlar uma área suficientemente produtiva para sustentar uma guarnição em tempos normais, mas ser grande e segura o suficiente para abrigar prover e proteger a guarnição quando submetida a um ataque (KEEGAN, 1994, pp. 155-156).

Por outro lado, o próprio vice-rei marquês do Lavradio (1769-1778) reconhecia as deficiências bélicas, técnicas e estratégicas do sistema defensivo da Ilha de Santa Catarina. Qualquer ação obsidional seria desastrosa. O conhecimento provinha pelo parecer do marechal Funck e do tenente-general João Henrique Böhm: "a defesa se devia reduzir ás partes mais próximas da mesma Ilha, e onde as forças estivessem mais juntas, para em um posto vantajoso fazerem a sua defesa". Os dois comandantes fizeram uma interpretação e uma análise do sistema defensivo na Barra Norte. A falha foi anunciada a Martinho de Melo e Castro, em 20 de novembro de 1776:

As fortalezas não estão nas grandes eminências que ela mostra; é verdade que há aqueles outeiros e rochedos, porém as baterias principais todas são baixas; é evidente que sendo assim elas não ficam superiores aos navios.

Depois disto ainda que aquelas fortalezas estejam em direção de cruzarem os seus tiros, a distância em que ficam umas das outras é tal, e tão larga a passagem que não só um tiro não cruza com o outro, mais os navios podem passar sem que nenhuma delas lhe possa fazer dano.

Além disto a construção das mesmas fortalezas é tão falta dos verdadeiros preceitos, que nenhuma delas poderá fazer uma vigorosa resistência se for atacada; depois disto elas são tão destacadas da Ilha, e com tão dificultosa communicação para se poderem retirar com brevidade á mesma Ilha, no caso de irem vendo que não podem sustentar resistência" (Bicentenário da volume 255, abr/jun., 1962, pp. 273-277). 
Na defesa do general Antônio Carlos Furtado de Mendonça, o comandante queixou-se excessivamente da relação conturbada com o governador Antônio da Gama Freitas. Os dois dividiam o governo da Ilha: Furtado de Mendonça, era responsável pelo comando militar, enquanto Grama Freitas pela política. Essa convivência foi prejudicial à prossecução do trabalho e, principalmente, à implantação de melhoras nas fortificações da Ilha. Furtado de Mendonça dizia que o governador arbitrariamente suspendia as construções, acometendo assim as atividades.

Falando o governador de Inhotomerim em uma ocasião na vila ao suplicante, lhe perguntou este pelo adiantamento das obras que lhe ordenara; respondeu que estavam suspensas pelo governador da ilha, a quem deu parte desta pergunta que o supplicante lhe tinha feito e ele lhe replicou arrogantemente que suspendesse tudo até ordem sua. Na fortaleza da Ponta Grossa tiha o suplicante mandado fazer umas plataformas, que a haver combate seriam indispensáveis, e, não as achando feitas quando em uma ocasião as ia visitar, perguntou a razão, e lhe respondeu o governador dela que o da ilha as mandara sobstar (Defesa de Antonio... 1864, tomo XXVII, pp. 291-331, p. 304).

As fortalezas construídas na Ilha de Santa Catarina ao longo do século XVIII são contemporizadas com as fortificações europeias do mesmo período. $\mathrm{O}$ desenho, a arquitetura e até mesmo o material utilizado eram semelhantes. Roberto Tonera, arquiteto e um dos responsáveis pelos trabalhos de remodelação das fortalezas da ilha e do empreendimento do Projeto Fortalezas Multimídia, trouxe novas visões sobre o sistema defensivo, contrariando a grande maioria que se debruçou nas construções, ressaltando em novos estudos que as fortalezas não eram tão ineficientes. Tonera lembra que as fortalezas da Ilha seguiam o mesmo padrão arquitetônico desenvolvido no resto da Europa. As técnicas de construção desenvolvidas no final do século XVII e início do século XVIII foram as orientações para o brigadeiro Silva Pais. Dessa forma,

[...] as fortificações catarinenses se diferenciam pelo fato de suas construções e praças de armas não estarem enclausuradas, contidas entre altas muralhas, adaptando-se de forma harmoniosa à topografia dos locais onde estão implantadas. Os edifícios sempre dispõem de uma vista privilegiada da paisagem circundante, sendo, portanto, também bastante visíveis do mar. Esta solução, utilizando muralhas baixas, o suficiente apenas para conter os terraplenos, e não para esconder as construções, seria um dos aspectos mais criticados do sistema defensivo projetado por Silva Paes, considerado por seus críticos muito "mais arquiteto que engenheiro militar". Mas, na realidade, tratava-se de um aperfeiçoamento na maneira de projetar fortificações, onde altas e inexpugnáveis muralhas (herança dos castelos 
medievais) não eram mais necessárias, em função da evolução da artilharia de longo alcance. Isto faz com que hoje as fortalezas de Santa Catarina, peculiarmente, assemelhem-se muito mais a Resorts voltados a uma exuberante paisagem natural, que a antigas praças de guerra (TONERA, $\mathrm{p}$. $3)$.

As fortalezas da Ilha de Santa Catarina, hoje sob os cuidados do IPHAN e da Universidade Federal da Ilha de Santa Catarina ${ }^{13}$, servem de patrimônio histórico e arquitetônico, além de paisagistíco. Duramente criticadas após a conquista, as fortalezas marcam o limiar da Ilha, da capitania e posteriormente do estado de Santa Catarina.

\section{FONTES CONSULTADAS}

Bicentenário da transferência da capital do estado do Brasil da cidade do Salvador para a cidade do Rio de Janeiro, correspondência do Conde de Azambuja e marquês do Lavradio, carta do marquês do Lavradio ao marquês de Pombal, Rio de Janeiro, 20 de novembro de 1776. Revista do Instituto Histórico e Geográfico Brasileiro. Rio de Janeiro, volume 255, abr/jun., 1962, p. 273-277.

Carta de Gomes Freire de Andrada a José da Silva Paes, Vila Rica, 15 de março de 1738. Revista Trimensal do Instituto Histórico Geographico e Ethnographico do Brasil. Rio de Janeiro: Garnier, 1869, tomo XXXII, parte $1^{\mathrm{a}}$, p. 109-125.

Carta de José Custodio de Sá e Faria para Francisco Xavier de Mendonça Furtado, Rio de Janeiro, 4 de abril de 1763. Revista Trimensal do Instituto Histórico, Geographico e Ethnographico do Brasil. Rio de Janeiro: Tipografia do Brazil, 1902, tomo LXV, primeira parte, p. 115-117.

Carta do brigadeiro José da Silva Paes, governador do Rio Grande de São Pedro ao general e vice-rei do Brasil Gomes Freire de Andrada, [Rio-Grande de São Pedro], 21 de junho de 1737. Revista Trimensal do Instituto Histórico Geographico e Ethnographico do Brasil. Rio de Janeiro: Garnier, 1869, tomo XXXII, parte $1^{\text {a }}$, p. 109-122; Consulta do Conselho Ultramarino, Lisboa, 3 de julho de 1748. Anais da Biblioteca Nacional. Rio de Janeiro: Editora do Livro, 1978, vol. 98, p. 216.

Carta do general Antônio Carlos Furtado de Mendonça, ao tenente-general João Henrique Boehm, Ilha de Santa Catarina, 30 de julho de 1775. Anais da Biblioteca Nacional. Rio de Janeiro, 1983, vol. 103, p. 50.

\footnotetext{
${ }^{13}$ Sobre os trabalhos de restauração das fortalezas, Ver: MACHADO, Rosangela M. de Melo. Fortalezas da Ilha de Santa Catarina: um panorama. Florianópolis: Imprensa Universitário da UFSC, 1994; SOUZA, Alcídio Mafra de. Guia dos Bens Tomados, Santa Catarina. Rio de Janeiro: Expressão e Cultura, 1992; SILVA, Rosemar da. Projeto Fortalezas da Ilha de Santa Catarina: uma ação de gestão universitária. (Dissertação) O Mestrado Profissional em Administração Universitária, UFSC, 2015.
} 
Carta do marquês de Pombal ao marquês do Lavradio, Palácio de Nossa Senhora da Ajuda, 9 de julho de 1774. Revista Trimensal do Instituto Histórico, Geographico e Ethnographico do Brasil. Rio de Janeiro: Garnier, 1868, tomo XXXI, parte primeira, p. 180-181-182; Marquês de Pombal, Plano militar da guerra, com que devemos repelir a aleivosa invasão que os Castelhanos intentam fazer em todas as partes do Sul do Brasil, por eles já aleivosamente ocupadas. Manuscrito do Instituto Histórico e Geográfico Brasileiro; Correspondência passiva do Tte.-Gal João Henrique de Böhm, Boletim do Centro Rio-Grandense de Estudos Históricos. Rio Grande, 1:13-14, out. 1939; Campaña del Brasil, Antecedentes coloniales. Archivo General de la Nación. Tomo III. Buenos Aires: Kraft, 1941, p. 295, nota 1; Catálogo de Manuscritos sobre Santa Catarina existentes na Biblioteca Nacional do Rio de Janeiro. Anais da Biblioteca Nacional. Rio de Janeiro: Editora do Livro, 1978, vol. 98 (208).

Cartas do Brigadeiro José da Silva Paes, Santa Catarina, 15 de fevereiro de 1748 e Lisboa, 21 de outubro de 1750. Annaes da Biblotheca Nacional do Rio de Janeiro. Officinas Graphicas da Bibliotheca Nacional, 1936 (1928), vol. 50, p. 117.

Conselho do Conselho Ultramarino, Lisboa, 3 de julho de 1748. Annaes da Biblotheca Nacional do Rio de Janeiro. Officinas Graphicas da Bibliotheca Nacional, 1936 (1928), vol. 50, p. 113-114.

Consulta do Conselho Ultramarino, Lisboa, 25 de fevereiro de 1743. Anais da Biblioteca Nacional. Rio de Janeiro: Editora do Livro, 1978, vol. 98, p. 215.

Consulta do Conselho Ultramarino, Lisboa, 29 de fevereiro de 1743. Anais da Biblioteca Nacional. Rio de Janeiro: Editora do Livro, 1978, vol. 98, p. 215.

Defesa de Antonio Carlos Furtado de Mendonça, respeito a entrega da Ilha de Santa Catarina. (Copiada de um manuscripto da Biblioteca Fluminense). Revista do Instituto Histórico e Geographico do Brazil. Rio de Janeiro: Typ. de Domingos Luiz dos Santos, 1864, tomo XXVII, p. 291-331, p. 304.

Oficio de Martinho de Melo e Castro ao marquês do Lavradio, Lisboa, 24 de janeiro; 14 de maio de 1775. Anais da Biblioteca Nacional. Rio de Janeiro: Editora do Livro, 1978, vol. 98, p. 221.

Oficio do Governador Manuel da Cunha Menezes para Martinho de Mello e Castro, Bahia, 12 de novembro de 1774. Anaes da Biblioteca Nacional do Rio de Janeiro. Officina Graphica da Bibliotheca Nacional, 1910, vol. 32, p. 284.

Ordem Régia, Lisboa, 7 de outubro de 1750. Annaes da Biblotheca Nacional do Rio de Janeiro. Officinas Graphicas da Bibliotheca Nacional, 1936 (1928), vol. 50, p. 114.

\section{REFERÊNCIAS}

BEBIANO, Rui. A pena de morte, escrita da guerra em Portugal e na Europa (séc. XVIXVIII). Coimbra: Edições Minerva, 2000. 
BOITEUX, Lucas Alexandre. Açorianos e madeirenses em Santa Catarina. Revista do Instituto Histórico e Geográfico Brasileiro. Volume 0219, 1953.

BRITO, Paulo José Miguel de. Memória política sobre a Capitania de Santa Catarina. Lisboa: Edição da Acadêmia de Ciências de Lisboa, 1829.

CABRAL, Oswaldo. Os açorianos. In: Anais do $1^{o}$ Congresso de história catarinense, Florianópolis. Imprensa Oficial do Estado. v. 2, 1950.

CALDAS, Marechal Candido. História Militar da Ilha de Santa Catarina, notas. Florianópolis: Lunardelli, 1992.

CANABRAVA, Alice Piffer. O comércio português no Rio da Prata, 1580-1640. São Paulo: Editora da Universidade de São Paulo, 1984.

CUSTÓDIO, José de Arimathéia Cordeiro. A arquitetura de defesa no Brasil colonial, discursos fotográficos. Londrina, v.7, n.10, p.173-194, jan./jun. 2011.

DORE, A. C. A fortaleza e o navio, espaços de reclusão na Carreira da Índia. Topoi (Rio de Janeiro). v. 9, p. 91-116, 2009.

GOLIN, Tau. A guerra guaranítica, como os exércitos de Portugal e Espanha destruíram os Sete Povos dos jesuítas e índios guaranis no Rio Grande do Sul. 2.ed. Passo Fundo: Ediupf, 1999.

HARO, Martim Afonso de Palma de. Ilha de Santa Catarina, relatos de viajantes estrangeiros nos séculos XVIII e XIX. 4ª . Ed. Florianópolis, UFSC/Lunardelli, 1996.

IZECKSOHN, Vitor. Ordenanças, tropas de linha e auxiliares: mapeando os espaços militares luso-brasileiros. In: FRAGOSO, João Luís Ribeiro; GOUVÊA, Maria de Fátima (org). $O$ Brasil colonial. volume 3 (ca. 1720-ca.1821). Rio de Janeiro, 2014.

KEEGAN, John. Uma história da guerra. Trad. Pedro Maia Soares. São Paulo: Companhia das Letras, 1994.

LAYTANO, Dante de. Corografia de Santa Catarina. Revista do Instituto Histórico e Geográfico Brasileiro. Rio de Janeiro, v. 245, out-dez, 1959, pp. 3-187.

MACHADO, Rosangela M. de Melo. Fortalezas da Ilha de Santa Catarina: um panorama. Florianópolis: Imprensa Universitário da UFSC, 1994.

MADEIRA, Artur Boavida. População e emigração nos Açores - 1766-1820. Cascais: Patrimonia, 1999.

MARTINELlO, André Souza. Geografia Histórica, discursos espaciais e construção territorial de Santa Catarina. Tese (Doutorado) em Geografia Humana, USP, 2016. 
MENESES, Avelino de Freitas. A conjuntura dos Açores à data da colonização setencista de Santa Catarina. In: Anais do Simpósio comemorativo ao cinqüentenario do $1^{\circ}$ Congresso de Historia Catarinense e 250 anos da presença açoriana em Santa Catarina. Florianópolis: Instituto Histórico e Geográfico de Santa Catarina, 1998, p. 41-52.

MENEZES, Avelino de Freitas. Os açorianos nas encruzilhadas de Setecentos II - economia. Ponta Delgada. Universidade dos Açores, 1995.

MENEZES, Avelino de Freitas. Os açorianos nas encruzilhadas de Setecentos I - poderes $e$ instituições. Ponta Delgada. Universidade dos Açores, 1993.

PIAZZA, F. Walter. Santa Catarina, sua história. Florianópolis: Ediufsc, Lunardelli, 1982.

PIAZZA, Walter F. A epopéia açórico-madeirense - 1748-1756. Florianópolis: Editora da UFSC, Editora Lunardelli, 1992.

PIAZZA, Walter F. O Brigadeiro José da Silva Paes: estruturador do Brasil Meridional. Florianópolis: FURG/UFSC, 1988.

PIAZZA, Walter F. O Povoamento Açoriano. In: Osvaldo Ferreira de Melo (Coord.). História Sócio-Cultural de Florianópolis. Florianópolis: Clube Doze de Agosto-Editora LunardelliIHGSC, pp. 53-89, 1991.

PRADO JR, Caio. Formação do Brasil contemporâneo, colônia. 2ed. São Paulo: Editora Brasiliense, 1953.

RODRIGUES, José Damião. Da periferia insular às fronteiras do império: colonos e recrutas dos Açores no povoamento da América. In, Anos 90, Porto Alegre, v. 17, n. 32, p. 17-43, dez. 2010 .

SILVA, Rosemar da. Projeto Fortalezas da Ilha de Santa Catarina: uma ação de gestão universitária. (Dissertação) O Mestrado Profissional em Administração Universitária, UFSC, 2015.

SOUZA, Alcídio Mafra de. Guia dos Bens Tomados, Santa Catarina. Rio de Janeiro: Expressão e Cultura, 1992.

SOUZA, Sara Regina Silveira de. A presença portuguesa na Arquitetura da Ilha de Santa Catarina. Florianópolis: Fcc, 1981.

TIRAPELI, Percival. Arte colonial, barroco e rococó. São Paulo: Companhia Editora Nacional, 2006.

TONERA, Roberto. O sistema defensivo da Ilha de Santa Catarina - Brasil: criação, abandono e recuperação. Ier Seminario Regional de Ciudades Fortificadas, 6 e 7 de abril de 2005, Montevideo-Uruguay; e Ferreira 2009. 
VARGAS, Milton (Org). História da técnica e da tecnologia do Brasil. São Paulo: Editora da Universidade Estadual Paulista, Centro Estadual de Educação Tecnológica Paula Souza, 1994.

WEIMER, Günter. Arquitetos imigrantes no Rio Grande do Sul. In: KOTHER, Maria Beatriz Medeiros; FERREIRA, Mario dos Santos; BREGATTO, Paulo Ricardo (orgs). Arquitetura e Urbanismo, postura, tendências \& reflexões. Edição de Textos comemorativos aos 10 anos da FAUPUCRS 1996-2006, Porto Alegre: EDIPUCRS, 2006.

WEIMER, Günter. As relações arquitetônicas rio-grandenses com o Prata. In: CLEMENTE, Evo. Integração, artes, letras e história. Porto Alegre: Edipucrs, 1995.

Recebido em: 31/05/2018 Aprovado em: 15/08/2018 